\title{
Recent Developments in Coal-Mining Explosives
}

$I^{N}$

British mines, about thirty million pounds weight of explosives are used annually. This involves the firing of about sixty million shots. When any shot is fired there is potential danger, particularly in gassy mines. Recent improvements in coal-mining explosives have aimed at increasing both their safety and efficiency. The three main developments have been (1) low-freezing explosives, (2) low-density explosives, and (3) 'Cardox'.

In a paper read recently before the Midland Institute of Mining Engineers, Dr. W. Payman, chief chemist to the Explosives in Mines Research Committee, discusses these developments. Nitro-glycerine freezes at $13^{\circ} \mathrm{C} .\left(55^{\circ} \mathrm{F}\right.$.) so that during storage in cold weather all explosives containing it become solid. Consequently many attempts have been made to render nitro-glycerine explosives non-freezing. The first method adopted in Great Britain was the substitution of a portion of the glycerine used in the manufacture of nitro-glycerine by polyglycerine. Though quite effective, this has now been replaced entirely by nitro-glycol. Polyglycerine was difficult to make and was not of constant composition. Glycol resembles glycerine in many respects and is largely used for preventing freezing in motor-car radiators. The efficacy of the use of low-freezing explosives is indicated by the fact that no fatal accident due to handling hard or frozen explosives has been roported for several years.

Low-density explosives have been developed mainly to reduce the shattering effect of high explosives and to increase the yield of lump coal. The average density of the new low-density explosives is about 0.7 , whereas that of the older explosives is 1.0 ; their respective weight-strengths, however, as judged by Government tests, are about the same. The decrease in density has been brought about by the incorporation with the explosive of bulky wood saw. dust or plant fibre. The reduced shattering effect of the low-density explosive appears to be due mainly to the spreading of the direct action of the explosive on the coal.

The introduction of 'Cardox' is one of the outstanding contributions to safety of recent years. The 'Cardox' blasting device consists of a strong steel shell containing a charge of liquid carbon dioxide and a heating element which converts the liquid carbon dioxide almost instantaneously into gas at high pressure. The pressure produced is sufficient to shear a disc at one end of the shell or cartridge, when the gas escapes and exerts a disruptive effect on the surrounding strata. The advantages claimed for the 'Cardox' blasting device are: (1) increased safety in the presence of firedamp and in handling; (2) increased yield of lump coal; (3) easy recovery of misfires; (4) little disturbing effect on roof near the shot-hole; and (5) absence of fumes.

It is encouraging to learn that the merits of the 'Lemaire sheath' are at last being given the serious attentiou of the Safety in Mines Research Board. This safety device consists of a thin cylinder of plastic clay mixad with sodium fluoride or another agent or both; the clay cylinder or 'sheath' envelops the explosive and largely damps out the flame resulting from its detonation. The Lemaire 'safety shoath' has been officially adopted in Belgium for many years.

\section{Radio Direction-Finding}

$A^{\mathrm{T}}$ a meeting of the Wire ess Section of the A Institution of Electrical Engineers held on April 5, two papers were read describing recent re. search carried out at H.M. Sicnal School in the development of radio direction-inders for use in naval ships. In the usual form of direction-finder, it is customary to employ a figure-of-eight reception characteristic for taking the direction, and then, by a separate operation, to resolve the $180^{\circ}$ ambiguity by determining the 'sense' of the bearing proviously obtained. The ordinary cardioid reception characteristic employed for the latter operation is not suitable for determining the bearing to any great accuracy, so that the two operations are necessary, involving an increase in the time required to obtain a bearing.

In one of the papers, entitled "A Radio Compass Developed in H.M. Signal School", Messrs. C. E. Horton and C. Crampton described a system whereby both the direction and the sense are determined by a single operation. The system employs two rotating loops or frame coils fixed together at right angles; one loop is arranged to give a figure-of-eight characteristic while the other gives a cardioid, the two characteristics being combined in such a way that the minimum of the cardioid is coincident in direction with one zero of the figure-of-eight. The paper included an analysis of the behaviour of such a direction-finding system, when installed in a steel ship, and also an account of experiments carried out to verify the results. It was shown that by a suitable arrangement of the circuits the errors in bearing due to currents set up in the ship itself can be reduced to the values obtained with the equivalent simple direction-finder in the same position.

The second paper, by Mr. J. F. Coales, comprised a calculation, with subsequent experimental measure. ment, of the magnitude of the errors experienced on a ship's direction-finder due to the shape and orientation of the aerial at the transmitting station. The experiments were carried out in a light cruiser, with a destroyer as the transmitting ship. The aerial on the latter was of the inverted ' $L$ ' type, and errors of $1^{\circ}$ or $2^{\circ}$ were found in the calibration of the direction. finder, when the receiving ship was not in line with the horizontal portion of the transmitting aerial. This error decreased rapidly with increasing distance between the two ships, becoming negligible at about four miles. A knowledge of this error is important in carrying out a calibration of the direction-finder at very short distances, and it is desirable to take two sets of readings, with the transmitting ship steaming round the receiving ship, first in a clockwise, and then in an anticlockwise direction. The mean of the readings so obtained will form a true calibration of the direction-finder for signals arriving from a distance. 